\title{
Steel alteration in different experimental engineered barrier environments
}

\author{
M. J. ROCK ${ }^{1 *}$, F.A. CAPORUSCIO ${ }^{1}$, K. B. SAUER ${ }^{1}$ \\ ${ }^{1}$ EES-14, Los Alamos National Laboratory, Los Alamos, NM \\ 87545 USA (*correspondence: mrock@lanl.gov)
}

The development and evaluation of engineered barrier system (EBS) designs and their potential interactions with natural barriers and other EBS interfaces are fundamentally important to the long-term safety and performance assessment of geologic repositories. The long-term repository safety relies upon continued steel canister integrity while in contact with EBS components (e.g., bentonite and cement) under repository conditions (increased temperatures, pressures). The focus of this experimental work is to characterize the interaction between the steel canister and other EBS materials under elevated temperatures and pressures associated with a geological repository in argillite host rock.

Hydrothermal experiments with Opalinus Clay host rock + Wyoming Bentonite \pm Portland Cement included steel coupons (304SS, 316SS, LCS) to understand steel corrosion and alteration phase mineralogy in a high temperature repository system $\left(200-300^{\circ} \mathrm{C}, 150\right.$ bars $)$. Experiments were conducted at $\sim 9: 1$ water:rock ratio for 6 to 8 weeks.

In the $300^{\circ} \mathrm{C}$ experiments without cement, $\mathrm{Fe}$-saponite, and minor pentlandite, chromite, pyrrhotite, and millerite formed perpendicular to stainless steel surfaces. Authigenic $\mathrm{Fe}$-saponite precipitated utilizing steel as a growth substrate and Fe supplied by steel corrosion. Alteration of smectite to Fe-saponite was only observed within $\sim 35-95 \mu \mathrm{m}$ from the steel coupon, indicating that Fe from steel corrosion did not migrate into the bentonite groundmass.

In the $200^{\circ} \mathrm{C}$ cement-bearing experiments, Fe-saponite growth was not observed on the surface of the steel coupons. Instead, mineral phases such as calcite, zeolites (garronite, analcime), $\mathrm{Fe}$-oxides, $\mathrm{Fe}-\mathrm{Ni}-\mathrm{Cr}$ sulfides/oxides, and $\mathrm{CSH}$ minerals (tobermorite) are observed to form a semicontinuous, $10-40 \mu \mathrm{m}$ thick layer at the steel interface.

These experimental results show that steel material may act as a reactive and dynamic substrate for mineral growth in response to corrosion. The bulk chemistry controls the alteration mineralogy, as demonstrated by the differences in mineral precipitation in the experiments with and without Portland Cement. The formation of surface-bound minerals is likely due to direct crystallization in the localized environments surrounding the metal. Future experiments will focus on the effect of these authigenic minerals on the performance of the repository system. 
This abstract is too long to be accepted for publication.

Please revise it so that it fits into the column on one page. 